Research Article

\title{
Free Vibrations and Impact Resistance of a Functionally Graded Honeycomb Sandwich Plate
}

\author{
Jun-hua Zhang $\mathbb{D}^{1}{ }^{1}$ Bao-juan Dong, ${ }^{2}$ Bince He, ${ }^{1}$ and Ying Sun ${ }^{1}$ \\ ${ }^{1}$ College of Mechanical Engineering, Beijing Information Science and Technology University, Beijing 100192, China \\ ${ }^{2}$ Heilongjiang College of Business and Technology, Harbin 150025, Heilongjiang, China \\ Correspondence should be addressed to Jun-hua Zhang; zjhuar@163.com
}

Received 4 July 2021; Revised 9 September 2021; Accepted 28 October 2021; Published 20 November 2021

Academic Editor: Zhaoye Qin

Copyright $(2021$ Jun-hua Zhang et al. This is an open access article distributed under the Creative Commons Attribution License, which permits unrestricted use, distribution, and reproduction in any medium, provided the original work is properly cited.

The functionally graded honeycomb has the characteristic of light weight, low density, high impact resistance, noise reduction, and energy absorption as a kind of new composite inhomogeneous materials. It has the advantages of both functionally graded materials and honeycombs. In this paper, a functionally graded honeycomb sandwich plate with functionally graded distributed along the thickness of the plate is constructed. The equivalent elastic parameters of the functionally graded honeycomb core are given. Based on Reddy's higher-order shear deformation theory (HSDT) and Hamilton's principle, the governing partial differential equation of motion is derived under four simply supported boundary conditions. The natural frequencies of the graded honeycomb sandwich plate are obtained by both the Navier method from the governing equation and the finite element model. The results obtained by the two methods are consistent. Based on this, the effects of parameters and graded on the natural frequencies of the functionally graded honeycomb sandwich plate are studied. Finally, the dynamic responses of the functionally graded honeycomb sandwich plate under low-speed impacts are studied. The results obtained in this paper will provide a theoretical basis for further study of the complex dynamics of functionally graded honeycomb structures.

\section{Introduction}

It is known that the functionally graded material (FGM) can be not only adapted to the need of modern high-tech areas like the aerospace industry but also satisfied with the limited environment and repeatedly used. Therefore, its properties have certain advantages compared with general composite materials [1]. Zhang et al. and Yao et al. [2,3] analyzed the nonlinear dynamics of FGM circular cylindrical shell with clamped-clamped edges. Hao et al. [4] studied the bendingtorsion coupling vibrations of a functionally graded sandwich panel. Liu et al. [5] investigated the nonlinear vibrations of the functionally graded shell with porosities on an elastic substrate.

The honeycombs are considered the best application prospect materials as super lightweight materials in many cellular materials [6]. Because honeycombs have many advantages such as energy absorption, buffering, heat insulation, noise elimination, light weight, and impact resistance. More and more research works are focused on honeycombs; for example, Hamidreza and Farid [7] studied the vibrational behaviors of auxetic honeycomb composite cylindrical shells subjected to moving pressures. Zhang et al. [8] analyzed the nonlinear responses of bioinspired auxetic honeycombs. Duc et al. [9] studied the dynamic response and vibration of a composite honeycomb sandwich plate and analyzed the influence of the geometric properties on the natural frequencies. The combination of functional graded materials and honeycomb can produce more excellent characteristics. The functionally graded honeycomb can be prepared for different fields such as aerospace, electronics, and medical devices.

The functionally graded honeycomb (FGH) sandwich plate is composed of upper and lower skins, and the honeycomb core layer and the graded are distributed along the length or thickness of the plate. It is a new engineering material integrated with physical and structural functions, which attracts a large number of scholars to study deeply in 
terms of strength, stiffness, and stability. The equivalent elastic parameters of the core layer are very important for the sandwich plate, and many researchers have proposed the formulas for the ordinary uniform honeycomb; for example, Gibson and Ashby [6] derived the equivalent elastic parameter formula of hexagonal honeycombs. Hui et al. [10] gave the strains and Poisson's ratios of auxetic honeycombs and the effect of the geometric parameters of the cell on the Poisson's ratios. $\mathrm{Xu}$ et al. [11] studied the in-plane mechanical properties of hybrid honeycombs and computed the equivalent elastic parameters. The equivalent elastic parameters for the functionally graded honeycomb layer were rarely seen.

It is known that the natural frequency of the plate or shell is one of the important characteristics of the structures. When designing a certain structure, researchers often pay attention to its natural frequency firstly. Zhang et al. [12] investigated the frequency responses of a 3D-Kagome truss core sandwich plate. Safaei and Fatahi [13] analyzed the free vibrations of new material structures as single-layered graphene sheets embedded in an elastic nonlocal plate. Safaei [14] studied damped vibrations of lightweight foam sandwich plates with composite faces.

In recent years, the impact resistance and energy absorption mechanism of the honeycomb sandwich plate have also become research hot topics. Palomba et al. [15] studied the deformation mode and energy absorption mechanism of the single-layer and double-layer honeycomb sandwich plates under the action of explosion load through experimental methods. Yu et al. [16] constructed a square honeycomb sandwich plate with in-plane graded and studied the impact resistance and energy absorption mechanism of the graded on the sandwich plate with finite element analysis. Xie et al. [17] studied the failure state and high-speed impact deformation mechanism of the honeycomb sandwich plate under high temperature by using the finite element method and phenomenological analysis. Ma et al. [18] designed five different honeycomb core layers for sandwich panels, and the energy absorption of graded honeycomb cores was analyzed. Arslan and Gunes [19] studied the mechanical behavior of the functionally graded honeycomb sandwich plate under high-speed impact by using a single-stage air gun through experiments and evaluated the failure and deformation mechanism of the specimen impact test results. Li et al. [20] studied the response of the three-layer graded honeycomb core sandwich plate under explosion load through experiments and analyzed the structural response by the finite element software.

In this paper, the equivalent elastic parameters for the functionally graded honeycomb core are given and then established the model of the sandwich plate with the functionally graded honeycomb core by using HSDT and Hamilton's principle. The natural frequencies are compared from the theoretical model and finite element model which prove the effectiveness of equivalent parameters and the model of the graded honeycomb sandwich plate. The frequency changes with the geometric parameters of the plate are obtained, and the vibration energy absorptions of auxetic functionally graded honeycomb panel are studied.

\section{FGH Sandwich Plate Model}

2.1. FGH Sandwich Plate. The functionally graded honeycomb sandwich plate consists of three layers, which are the upper surface, honeycomb core, and lower surface from top to bottom, respectively, as shown in Figure 1. The coordinate system is established in the central cross section of the plate, and the displacements at any point in the central plane in the $x, y$, and $z$ directions are represented as $u, \mathrm{v}$, and $w$, respectively. The thickness of the whole sandwich plate and honeycomb core is $h$ and $h c$, respectively. The length and width of the plate are represented by $a$ and $b$, respectively. Suppose that the honeycomb core layer is tightly bonded to the skins on both sides, and the thickness of the skin is very thin compared to the thickness of the honeycomb core layer. Therefore, the influence of the skin on the deformation of the honeycomb core layer is ignored, and the deformation of the whole plate is continuous.

2.2. The Form of Functionally Graded. It is assumed that the material properties change continuously in the direction of thickness, and the two types of the FGH sandwich plate are discussed as Type A and Type B. The coordinate system is set in Figure 1 at $z= \pm h / 2\left(\xi_{1}=-h / 2, \xi_{4}=+h / 2\right)$, and the middle two interfaces are represented by $\xi_{2}$ and $\xi_{3}$, respectively.

\subsubsection{Type A: Functionally Graded Surface and Homogeneous} Honeycomb Core. The FGH sandwich plate is composed of two functionally graded surfaces and a homogeneous honeycomb core, as shown in Figure 2. The two functionally graded surfaces are composed of metal and ceramic materials, and the honeycomb core is made of homogeneous ceramics. The content of ceramics can be expressed in the form of a volume fraction [21]:

$$
\begin{aligned}
& V_{1}(z)=\left(\frac{z-\xi_{1}}{\xi_{2}-\xi_{1}}\right)^{N}, \quad z \in\left[-\frac{h}{2}, \xi_{2}\right], \\
& V_{2}(z)=1, \quad z \in\left[\xi_{2}, \xi_{3}\right], \\
& V_{3}(z)=\left(\frac{z-\xi_{4}}{\xi_{3}-\xi_{4}}\right)^{N}, \quad z \in\left[\xi_{3}, \frac{h}{2}\right],
\end{aligned}
$$

where $V_{1}, V_{2}$, and $V_{3}$ are the volume fraction of the upper surface layer, honeycomb core layer, and lower surface layer from top to bottom, respectively, and $N$ represents the volume fraction index. The core of the plate is composed of homogeneous ceramics. Therefore, the volume fraction is 1 , as shown in equation (1b). Since the volume fraction is less than 1, as shown in equations (1a) and (1c), the volume fraction of the ceramic decreases correspondingly when the power-law exponent $N$ increases.

\subsubsection{Type B: Homogeneous Surface and Functionally Graded} Honeycomb Core. The two surface layers are homogeneous, and the honeycomb core is the functionally graded material 


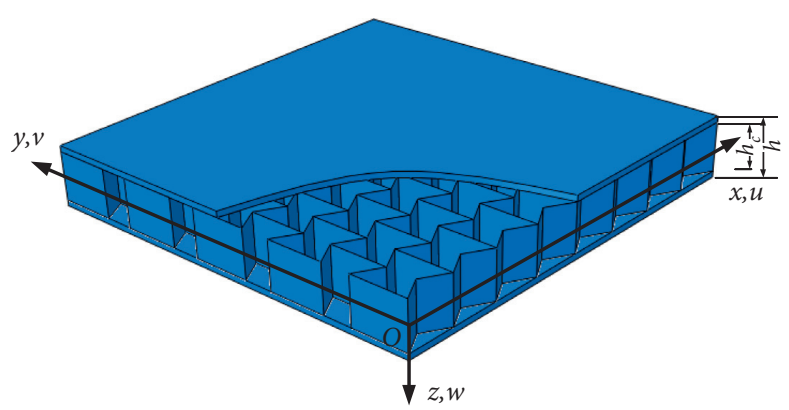

FIgURE 1: Geometry of the FGH sandwich plate.

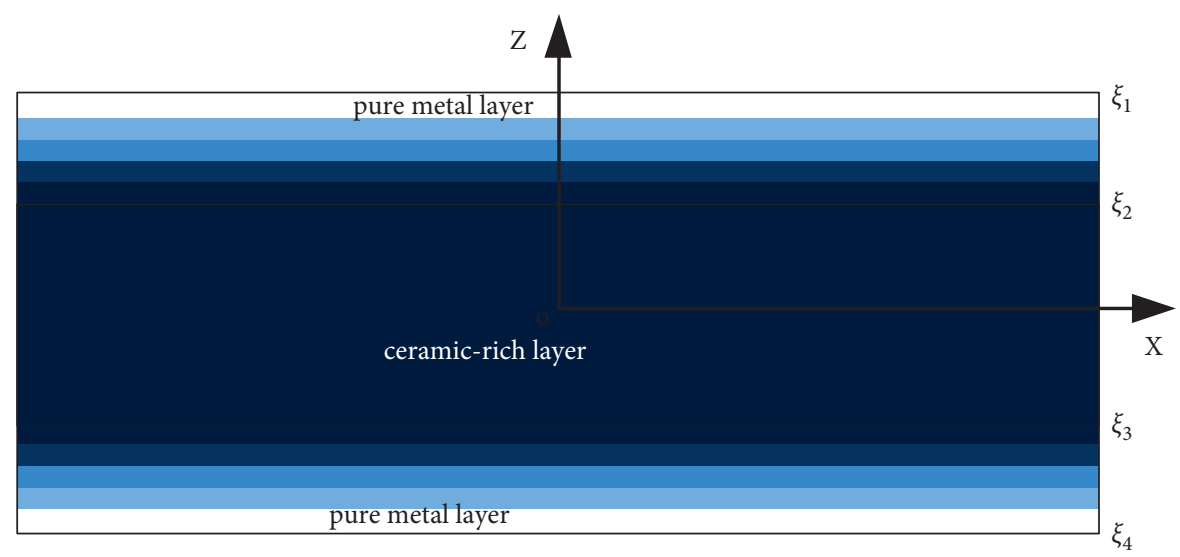

FIGURE 2: Type-A FGM face sheet and homogeneous honeycomb core.

in type B, as shown in Figure 3. The upper and lower layers are homogeneous metal and ceramic materials, respectively, and the core layer is composed of functionally graded materials. The metal content is expressed in the form of the volume fraction as follows:

$$
\begin{aligned}
& V_{1}(z)=0, \quad z \in\left[-\frac{h}{2}, \xi_{2}\right], \\
& V_{2}(z)=\left(\frac{z-\xi_{2}}{\xi_{3}-\xi_{2}}\right)^{N}, \quad z \in\left[\xi_{2}, \xi_{3}\right], \\
& V_{3}(z)=1, \quad z \in\left[\xi_{3}, \frac{h}{2}\right] .
\end{aligned}
$$

It is assumed that the material composition changes graded in the $z$ direction and conforms to the power-law distribution. For the physical parameters of each layer, namely, Young's modulus $E^{(k)}$, shear modulus $G^{(k)}$, Poisson's ratio $\nu$, and density $\rho^{(k)}$ can be obtained from the following formula:

$$
P^{(k)}(z)=P_{m} V_{m}+P_{c} V_{c},
$$

where $k=1,3$ are the upper and lower surface, respectively, $k=2$ represents the core layer of the honeycombs, $P_{c}$ and $P_{m}$ represent the physical parameters of the ceramics and metals, respectively, and $V_{c}$ and $V_{m}$ are the volume fractions of component materials along the $z$ direction. The relationship between the volume fractions of the metals and ceramics is

$$
\begin{aligned}
& V_{m}+V_{c}=1, \\
& V_{c}=\left(\frac{z}{h}+\frac{1}{2}\right)^{N}, \quad N \geq 0 .
\end{aligned}
$$

2.3. The Equivalent Elastic Parameters of the FGH Sandwich Plate. Figure 4 shows the cellular structure of a concave hexagonal honeycomb core, where $l_{1}, l_{2}, t_{1}, t_{2}\left(t_{1}=t_{2}\right)$, and $\theta$ represent the length of the inclined siding, the length of the straight siding, the thickness of the cell slant, the thickness of the straight wall, and the cell inclination angle, respectively. Based on the formulas for the honeycomb cores in literature [22], combined with the volume fractions above, it can be obtained by the equivalent elastic parameter formula of the functionally graded honeycomb core as follows: 


$$
\begin{aligned}
& E_{1}^{(2)}=E_{\mathrm{ms}} V_{m} \frac{\eta_{3}^{3}\left(\eta_{1}-\sin \theta\right)}{\cos ^{3} \theta\left[1+\left(\tan ^{2} \theta+\eta_{1} \sec ^{2} \theta\right) \eta_{3}^{2}\right]}+E_{\mathrm{cs}} V_{c} \frac{\eta_{3}^{3}\left(\eta_{1}-\sin \theta\right)}{\cos ^{3} \theta\left[1+\left(\tan ^{2} \theta+\eta_{1} \sec ^{2} \theta\right) \eta_{3}^{2}\right]} \\
& E_{2}^{(2)}=E_{\mathrm{ms}} V_{m} \frac{\eta_{3}^{3}}{\cos \theta\left(\eta_{1}-\sin \theta\right)\left(\tan ^{2} \theta+\eta_{3}^{2}\right)}+E_{\mathrm{cs}} V_{c} \frac{\eta_{3}^{3}}{\cos \theta\left(\eta_{1}-\sin \theta\right)\left(\tan ^{2} \theta+\eta_{3}^{2}\right)}, \\
& G_{12}^{(2)}=E_{\mathrm{ms}} V_{m} \frac{\eta_{3}^{3}}{\eta_{1}\left(1+2 \eta_{1}\right) \cos \theta} \\
& G_{23}^{(2)}=G_{\mathrm{ms}} V_{m} \frac{\eta_{3} \cos \theta}{\eta_{1}-\sin \theta}+G_{\mathrm{cs}} V_{c} \frac{\eta_{3} \cos \theta}{\eta_{1}-\sin \theta}+E_{\mathrm{cs}} V_{c} \frac{\eta_{3}^{3}}{\eta_{1}\left(1+2 \eta_{1}\right) \cos \theta}, \\
& G_{31}^{(2)}=G_{\mathrm{ms}} V_{m} \frac{\eta_{3}}{2 \cos \theta}\left[\frac{\eta_{1}-\sin \theta}{1+2 \eta_{1}}+\frac{\eta_{1}+2 \sin ^{2} \theta}{2\left(\eta_{1}-\sin \theta\right)}\right]+G_{\mathrm{cs}} V_{c} \frac{\eta_{3}}{2 \cos \theta}\left[\frac{\eta_{1}-\sin \theta}{1+2 \eta_{1}}+\frac{\eta_{1}+2 \sin ^{2} \theta}{2\left(\eta_{1}-\sin \theta\right)}\right], \\
& v_{12}^{(2)}=-\frac{\sin \theta\left(1-\eta_{3}^{2}\right)\left(\eta_{1}-\sin \theta\right)}{\cos ^{2} \theta\left[1+\left(\tan ^{2} \theta+\sec ^{2} \theta \eta_{1}\right) \eta_{3}^{2}\right]} V_{m}-\frac{\sin \theta\left(1-\eta_{3}^{2}\right)\left(\eta_{1}-\sin \theta\right)}{\cos ^{2} \theta\left[1+\left(\tan ^{2} \theta+\sec ^{2} \theta \eta_{1}\right) \eta_{3}^{2}\right]} V_{c} \\
& v_{21}^{(2)}=-\frac{\sin \theta\left(1-\eta_{3}^{2}\right)}{\left(\tan ^{2} \theta+\eta_{3}^{2}\right)\left(\eta_{1}-\sin \theta\right)} V_{m}-\frac{\sin \theta\left(1-\eta_{3}^{2}\right)}{\left(\tan ^{2} \theta+\eta_{3}^{2}\right)\left(\eta_{1}-\sin \theta\right)} V_{c}, \\
& \rho^{(2)}=\rho_{\mathrm{ms}} \frac{\eta_{3}\left(\eta_{1}+2\right)}{2 \cos \theta\left(\eta_{1}-\sin \theta\right)} V_{m}+\rho_{\mathrm{cs}} \frac{\eta_{3}\left(\eta_{1}+2\right)}{2 \cos \theta\left(\eta_{1}-\sin \theta\right)} V_{c},
\end{aligned}
$$

where $\eta_{1}=l_{2} / l_{1}, \eta_{2}=t_{2} / t_{1}$, and $\eta_{3}=t_{1} / l_{1}$. Subscripts $m s$ and $c s$ represent the subscripts for the corresponding material parameters of the metals and ceramics, respectively.

2.4. Equations Motion of the FGH Sandwich Plate. According to Reddy's higher-order shear deformation theory, the displacement field is selected as the following form:

$$
\begin{gathered}
u(x, y, z, t)=u_{0}(x, y, t)+z \phi_{x}(x, y, t)-\frac{4}{3 h^{2}} z^{3}\left(\phi_{x}+\frac{\partial w_{0}}{\partial x}\right), \\
v(x, y, z, t)=v_{0}(x, y, t)+z \phi_{y}(x, y, t)-\frac{4}{3 h^{2}} z^{3}\left(\phi_{y}+\frac{\partial w_{0}}{\partial y}\right), \\
w(x, y, z, t)=w_{0}(x, y, t),
\end{gathered}
$$

where $h$ is the thickness of the honeycomb sandwich plate and $u_{0}, v_{0}, w_{0}, \phi_{x}$, and $\phi_{y}$ are the axial displacement, lateral displacement, and rotation angle of the middle plane, respectively. According to the Von-Karman large deformation relation, the expression of $\varepsilon_{i}(i=\mathrm{xx}, \mathrm{yy})$ and $\gamma_{i}(i=$ $\mathrm{xy}, \mathrm{yz}, \mathrm{zx})$ strain-displacement relation can be obtained as

$$
\begin{aligned}
& \varepsilon_{\mathrm{xx}}=\frac{\partial u}{\partial x}+\frac{1}{2}\left(\frac{\partial w}{\partial x}\right)^{2}, \\
& \varepsilon_{\mathrm{yy}}=\frac{\partial v}{\partial y}+\frac{1}{2}\left(\frac{\partial w}{\partial y}\right)^{2}, \\
& \gamma_{\mathrm{xz}}=\frac{1}{2}\left(\frac{\partial u}{\partial z}+\frac{\partial w}{\partial x}\right), \\
& \gamma_{\mathrm{yz}}=\frac{1}{2}\left(\frac{\partial v}{\partial z}+\frac{\partial w}{\partial y}\right), \\
& \gamma_{\mathrm{xy}}=\frac{\partial u}{\partial y}+\frac{\partial v}{\partial x}+\frac{\partial w}{\partial x} \frac{\partial w}{\partial y}, \\
& \varepsilon_{\mathrm{zz}}=\frac{\partial w}{\partial z} .
\end{aligned}
$$




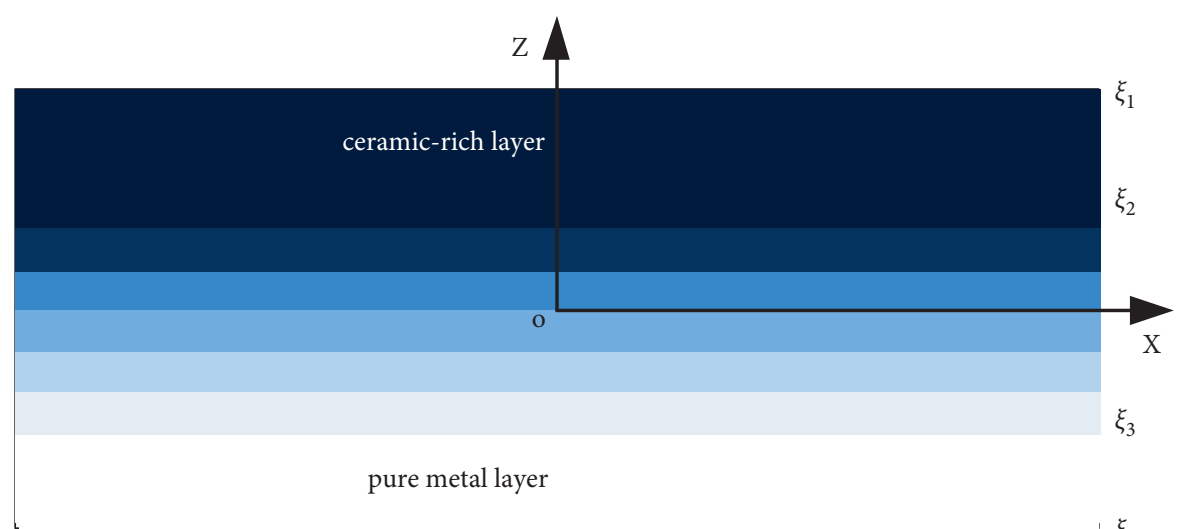

Figure 3: Type-B homogeneous faces sheet and FGH core.

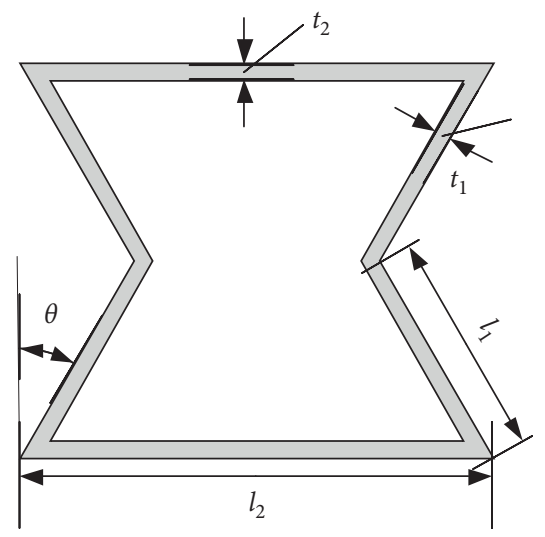

Figure 4: The unit cell of concave hexagonal honeycomb core.

From equations (6) and (7) we can obtain:

$$
\begin{aligned}
\left\{\begin{array}{c}
\varepsilon_{\mathrm{xx}} \\
\varepsilon_{\mathrm{yy}} \\
\gamma_{\mathrm{xy}}
\end{array}\right\} & =\left\{\begin{array}{c}
\varepsilon_{\mathrm{xx}}^{(0)} \\
\varepsilon_{\mathrm{yy}}^{(0)} \\
\gamma_{\mathrm{xy}}^{(0)}
\end{array}\right\}+z\left\{\begin{array}{c}
\varepsilon_{\mathrm{xx}}^{(1)} \\
\varepsilon_{\mathrm{yy}}^{(1)} \\
\gamma_{\mathrm{xy}}^{(1)}
\end{array}\right\}+z^{3}\left\{\begin{array}{c}
\varepsilon_{\mathrm{xx}}^{(3)} \\
\varepsilon_{\mathrm{yy}}^{(3)} \\
\gamma_{\mathrm{xy}}^{(3)}
\end{array}\right\}, \\
\left\{\begin{array}{l}
\gamma_{\mathrm{yz}} \\
\gamma_{\mathrm{xz}}
\end{array}\right\} & =\left\{\begin{array}{c}
\gamma_{\mathrm{yz}}^{(0)} \\
\gamma_{\mathrm{xz}}^{(0)}
\end{array}\right\}+z^{2}\left\{\begin{array}{c}
\gamma_{\mathrm{yz}}^{(2)} \\
\gamma_{\mathrm{xz}}^{(2)}
\end{array}\right\} .
\end{aligned}
$$

The honeycomb sandwich plate with the negative Poisson's ratio is the anisotropic laminated plate, so the constitutive equation can be written as

$$
\left\{\begin{array}{c}
\sigma_{\mathrm{xx}} \\
\sigma_{\mathrm{yy}} \\
\sigma_{\mathrm{yz}} \\
\sigma_{\mathrm{xz}} \\
\sigma_{\mathrm{xy}}
\end{array}\right\}=\left\{\begin{array}{ccccc}
Q_{11}^{(k)} & Q_{12}^{(k)} & 0 & 0 & 0 \\
Q_{21}^{(k)} & Q_{22}^{(k)} & 0 & 0 & 0 \\
0 & 0 & Q_{44}^{(k)} & 0 & 0 \\
0 & 0 & 0 & Q_{55}^{(k)} & 0 \\
0 & 0 & 0 & 0 & Q_{66}^{(k)}
\end{array}\right\}\left\{\begin{array}{c}
\varepsilon_{\mathrm{xx}} \\
\varepsilon_{\mathrm{yy}} \\
\gamma_{\mathrm{yz}} \\
\gamma_{\mathrm{xz}} \\
\gamma_{\mathrm{xy}}
\end{array}\right\},
$$

where the stiffness coefficient can be expressed as

$$
\begin{gathered}
Q_{11}^{(k)}=\frac{E_{1}^{(k)}}{1-v_{12}^{(k)} v_{21}^{(k)}}, \\
Q_{12}^{(k)}=\frac{E_{1}^{(k)} v_{12}^{(k)}}{1-v_{12}^{(k)} v_{21}^{(k)}}, \\
Q_{22}^{(k)}=\frac{E_{2}^{(k)}}{1-v_{12}^{(k)} v_{21}^{(k)}}, \\
Q_{66}=G_{12}, \\
Q_{44}=G_{23}, \\
Q_{55}=G_{13}, \\
Q_{21}=Q_{12},
\end{gathered}
$$

where $E_{1}^{(k)}, E_{2}^{(k)}, G_{12}^{(k)}, G_{13}^{(k)}, G_{23}^{(k)}, v_{12}^{(k)}$, and $v_{21}^{(k)}$ are the elastic modulus, shear modulus, and Poisson's ratio of the skin and core layer, respectively. The superscript $k=1,3$ represents the upper and lower surface. The parameters are from equation (3). $k=2$ represents the honeycomb core layer. The equivalent elastic parameters of the honeycomb core layer are calculated by formula (5).

According to Hamilton's principle, the nonlinear governing equation of a honeycomb sandwich board is obtained. Hamilton's principle can be expressed as follows:

$$
\int_{t_{1}}^{t_{2}}(\delta U-\delta K) \mathrm{d} t+=0 .
$$

For the honeycomb sandwich plate with the negative Poisson's ratio, the kinetic energy $\delta K$, potential energy $\delta U$, and external virtual work $\delta W$ of the system are expressed as

$$
\begin{aligned}
\delta K= & \int_{\Omega_{0}}\left[\left(I_{0} \dot{u}_{0}+I_{1} \dot{\phi}_{x}-c_{1} I_{3} \dot{\varphi}_{x}\right) \delta \dot{u}_{0}+\left(I_{1} \dot{u}_{0}+I_{2} \dot{\phi}_{x}-c_{1} I_{4} \dot{\varphi}_{x}\right) \delta \dot{\phi}_{x}\right. \\
& -c_{1}\left(I_{3} \dot{u}_{0}+I_{4} \dot{\phi}_{x}-c_{1} I_{6} \dot{\varphi}_{x}\right) \delta \dot{\phi}_{x}+\left(I_{0} \dot{v}_{0}+I_{1} \dot{\phi}_{y}-c_{1} I_{3} \dot{\varphi}_{y}\right) \delta \dot{v}_{0} \\
& +\left(I_{1} \dot{v}_{0}+I_{2} \dot{\phi}_{y}-c_{1} I_{4} \dot{\varphi}_{y}\right) \delta \dot{\phi}_{y}-c_{1}\left(I_{3} \dot{u}_{0}+I_{4} \dot{\phi}_{y}-c_{1} I_{6} \dot{\varphi}_{y}\right) \delta \dot{\varphi}_{y} \\
& +\left(I_{0} \dot{v}_{0}+I_{1} \dot{\phi}_{y}-c_{1} I_{3} \dot{\varphi}_{y}\right) \delta \dot{v}_{0}+\left(I_{1} \dot{v}_{0}+I_{2} \dot{\phi}_{y}-c_{1} I_{4} \dot{\varphi}_{y}\right) \delta \dot{\phi}_{y} \\
& \left.-c_{1}\left(I_{3} \dot{u}_{0}+I_{4} \dot{\phi}_{y}-c_{1} I_{6} \dot{\varphi}_{y}\right) \delta \dot{\varphi}_{y}-I_{0} \dot{w}_{0} \delta \dot{w}_{0}\right] \mathrm{d} x \mathrm{~d} y .
\end{aligned}
$$


Among them,

$$
\begin{aligned}
\dot{\varphi}_{x}= & \dot{\phi}_{x}+\frac{\partial w_{0}}{\partial x} \\
\dot{\varphi}_{y}= & \dot{\phi}_{y}+\frac{\partial w_{0}}{\partial y}, \\
\delta U= & \int_{\Omega_{0}}\left[N_{x x} \delta \varepsilon_{x x}^{(0)}+M_{x x} \delta \varepsilon_{x x}^{(1)}-c_{1} P_{x x} \delta \varepsilon_{x x}^{(3)}+N_{y y} \delta \varepsilon_{y y}^{(0)}+M_{y y} \delta \varepsilon_{y y}^{(1)}-c_{1} P_{y y} \delta \varepsilon_{y y}^{(3)}\right. \\
& \left.+N_{x y} \delta \gamma_{x y}^{(0)}+M_{x y} \delta \gamma_{x y}^{(1)}-c_{1} P_{x y} \delta \gamma_{x y}^{(3)}+Q_{x} \delta \gamma_{x z}^{(0)}-c_{2} R_{x} \delta \gamma_{x z}^{(0)}+Q_{y} \delta \gamma_{y z}^{(0)}-c_{2} R_{y} \delta \gamma_{y z}^{(0)}\right] \mathrm{d} x \mathrm{~d} y, \\
\delta W= & \int_{\Omega_{0}} F \delta w_{0} \mathrm{~d} x \mathrm{~d} y-\int_{\Omega_{0}} \gamma \delta \dot{w}_{0} \mathrm{~d} x \mathrm{~d} y,
\end{aligned}
$$

where $\Omega_{0}$ represents the mid-plane of the plate.

$$
\begin{aligned}
\left\{\begin{array}{c}
N_{\alpha \beta} \\
M_{\alpha \beta} \\
P_{\alpha \beta}
\end{array}\right\} & =\int_{-h / 2}^{h / 2} \sigma_{\alpha \beta}\left\{\begin{array}{c}
1 \\
z \\
z^{3}
\end{array}\right\} \mathrm{d} z \\
\left\{\begin{array}{c}
Q_{\alpha} \\
R_{\alpha}
\end{array}\right\} & =\int_{-h / 2}^{h / 2} \sigma_{\alpha z}\left\{\begin{array}{c}
1 \\
z^{2}
\end{array}\right\} \mathrm{d} z \\
I_{i} & =\int_{-h / 2}^{h / 2} \rho_{s}(z)^{i} \mathrm{~d} z, \quad(i=0,1,2, \ldots, 6)
\end{aligned}
$$

where subscripts $\alpha$ and $\beta$ denote $x$ and $y$, and $N, M$, and $I$ represent the surface internal force, moment of torque, and moment of mass of inertia, respectively.

By substituting equation (12) into (11), the nonlinear dynamic equation of the honeycomb sandwich plate can be obtained as follows:

$$
\begin{gathered}
\frac{\partial N_{x x}}{\partial x}+\frac{\partial N_{x y}}{\partial y}=I_{0} \ddot{u}_{0}+J_{1} \ddot{\phi}_{x}-c_{1} I_{3} \frac{\partial \ddot{w}_{0}}{\partial x} \\
\frac{\partial N_{x y}}{\partial x}+\frac{\partial N_{y y}}{\partial y}=I_{0} \ddot{v}_{0}+J_{1} \ddot{\phi}_{y}-c_{1} I_{3} \frac{\partial \ddot{w}_{0}}{\partial y}, \\
\frac{\partial \bar{Q}_{x}}{\partial x}+\frac{\partial \bar{Q}_{y}}{\partial y}+\frac{\partial}{\partial x}\left(N_{x x} \frac{\partial w_{0}}{\partial x}+N_{x y} \frac{\partial w_{0}}{\partial y}\right)+\frac{\partial}{\partial y}\left(N_{x y} \frac{\partial w_{0}}{\partial x}+N_{y y} \frac{\partial w_{0}}{\partial y}\right)+c_{1}\left(\frac{\partial^{2} P_{x x}}{\partial x^{2}}+2 \frac{\partial^{2} P_{x y}}{\partial x \partial y}+\frac{\partial^{2} P_{y y}}{\partial y^{2}}\right)=I_{0} \ddot{w}_{0} \\
-c_{1}^{2} I_{6}\left(\frac{\partial^{2} \ddot{w}_{0}}{\partial x^{2}}+\frac{\partial^{2} \ddot{w}_{0}}{\partial y^{2}}\right)+c_{1}\left[I_{3}\left(\frac{\partial \ddot{u}_{0}}{\partial x}+\frac{\partial \ddot{v}_{0}}{\partial y}\right)+J_{4}\left(\frac{\partial \ddot{\phi}_{x}}{\partial x}+\frac{\partial \ddot{\phi}_{y}}{\partial y}\right)\right], \\
\frac{\partial \bar{M}_{x x}}{\partial x}+\frac{\partial \bar{M}_{x y}}{\partial y}-\bar{Q}_{x}=J_{1} \ddot{u}_{0}+K_{2} \ddot{\phi}_{x}-c_{1} J_{4} \frac{\partial \ddot{w}_{0}}{\partial x} \\
\frac{\partial \bar{M}_{x y}}{\partial x}+\frac{\partial \bar{M}_{y y}}{\partial y}-\bar{Q}_{y}=J_{1} \ddot{v}_{0}+K_{2} \ddot{\phi}_{y}-c_{1} J_{4} \frac{\partial \ddot{w}_{0}}{\partial y} .
\end{gathered}
$$


Among them,

$$
\begin{aligned}
\bar{M}_{\alpha \beta} & =M_{\alpha \beta}-c_{1} P_{\alpha \beta}, \quad(\alpha, \beta=1,2,6), \\
\bar{Q}_{\alpha} & =Q_{\alpha}-c_{2} R_{\alpha}, \quad(\alpha=4,5), \\
I_{i} & =\sum_{k=1}^{N} \int_{z_{k}}^{z_{k+1}} \rho^{(k)}(z)^{i} \mathrm{~d} z, \quad(i=0,1,2, \ldots, 6),
\end{aligned}
$$

$$
\begin{aligned}
J_{i} & =I_{i}-c_{1} I_{i+2}, \\
K_{2} & =I_{2}-2 c_{1} I_{4}+c_{1}^{2} I_{6}, \\
c_{1} & =\frac{4}{3 h^{2}}, \\
c_{2} & =3 c_{1} .
\end{aligned}
$$
form:

$$
\begin{aligned}
& \left\{\begin{array}{l}
N_{x x} \\
N_{y y} \\
N_{x y}
\end{array}\right\}=\left\{\begin{array}{ccc}
A_{11} & A_{12} & 0 \\
A_{21} & A_{22} & 0 \\
0 & 0 & A_{66}
\end{array}\right\}\left\{\begin{array}{c}
\varepsilon_{x x}^{(0)} \\
\varepsilon_{y y}^{(0)} \\
\gamma_{x y}^{(0)}
\end{array}\right\} \\
& \left\{\begin{array}{l}
M_{x x} \\
M_{y y} \\
M_{x y}
\end{array}\right\}=\left\{\begin{array}{ccc}
D_{11} & D_{12} & 0 \\
D_{21} & D_{22} & 0 \\
0 & 0 & D_{66}
\end{array}\right\}\left\{\begin{array}{c}
\varepsilon_{x x}^{(1)} \\
\varepsilon_{y y}^{(1)} \\
\gamma_{x y}^{(1)}
\end{array}\right\}+\left\{\begin{array}{ccc}
F_{11} & F_{12} & 0 \\
F_{21} & F_{22} & 0 \\
0 & 0 & F_{66}
\end{array}\right\}\left\{\begin{array}{c}
\varepsilon_{x x}^{(3)} \\
\varepsilon_{y y}^{(3)} \\
\gamma_{x y}^{(3)}
\end{array}\right\} \\
& \left\{\begin{array}{l}
P_{x x} \\
P_{y y} \\
P_{x y}
\end{array}\right\}=\left\{\begin{array}{ccc}
F_{11} & F_{12} & 0 \\
F_{21} & F_{22} & 0 \\
0 & 0 & F_{66}
\end{array}\right\}\left\{\begin{array}{c}
\varepsilon_{x x}^{(1)} \\
\varepsilon_{y y}^{(1)} \\
\gamma_{x y}^{(1)}
\end{array}\right\}+\left\{\begin{array}{ccc}
H_{11} & H_{12} & 0 \\
H_{21} & H_{22} & 0 \\
0 & 0 & H_{66}
\end{array}\right\}\left\{\begin{array}{c}
\varepsilon_{x x}^{(3)} \\
\varepsilon_{y y}^{(3)} \\
\gamma_{x y}^{(3)}
\end{array}\right\} \\
& \left\{\begin{array}{l}
Q_{y} \\
Q_{x}
\end{array}\right\}=\left\{\begin{array}{cc}
A_{44} & 0 \\
0 & A_{55}
\end{array}\right\}\left\{\begin{array}{l}
\gamma_{y z}^{(0)} \\
\gamma_{x z}^{(0)}
\end{array}\right\}+\left\{\begin{array}{cc}
D_{44} & 0 \\
0 & D_{55}
\end{array}\right\}\left\{\begin{array}{l}
\gamma_{y z}^{(2)} \\
\gamma_{x z}^{(2)}
\end{array}\right\} \\
& \left\{\begin{array}{l}
R_{y} \\
R_{x}
\end{array}\right\}=\left\{\begin{array}{cc}
D_{44} & 0 \\
0 & D_{55}
\end{array}\right\}\left\{\begin{array}{l}
\gamma_{y z}^{(0)} \\
\gamma_{x z}^{(0)}
\end{array}\right\}+\left\{\begin{array}{cc}
F_{44} & 0 \\
0 & F_{55}
\end{array}\right\}\left\{\begin{array}{l}
\gamma_{y z}^{(2)} \\
\gamma_{x z}^{(2)}
\end{array}\right\}
\end{aligned}
$$

The stiffness matrix of the laminated plate is expressed as follows:

$$
\begin{gathered}
\left(A_{i j}, D_{i j}, F_{i j}, H_{i j}\right)=\int_{-h / 2}^{h / 2} Q_{i j}\left(1, z^{2}, z^{4}, z^{6}\right) \mathrm{d} z, \quad(i, j=1,2,6), \\
\left(A_{i j}, D_{i j}, F_{i j}\right)=\int_{-h / 2}^{h / 2} Q_{i j}\left(1, z^{2}, z^{4}\right) \mathrm{d} z, \quad(i, j=4,5) .
\end{gathered}
$$

Substituting equations (16) and (17) into (14), the nonlinear dynamic equation of the functionally graded honeycomb sandwich plate in the displacement form can be obtained; due to space limitations, it is omitted here.

\section{Boundary Conditions and Navier Method}

Assuming that the boundary condition of simple support in four sides be the following equations:

$$
\text { when } x=0 \text { and } x=a, v_{0}=w_{0}=\phi_{y}=N_{x x}=\bar{M}_{x x}=0 \text {, }
$$

when $y=0$ and $y=b, u_{0}=w_{0}=\phi_{x}=N_{y y}=\bar{M}_{y y}=0$.

According to the Navier method, the displacement component of the honeycomb plate system under the condition of simple support of four sides $u_{0}, v_{0}, w_{0}, \phi_{x}$, and $\phi_{y}$ can be expressed respectively as

$$
\begin{aligned}
& u_{0}=\sum_{m=1}^{\infty} \sum_{n=1}^{\infty} U_{\mathrm{mn}}(t) \cos (\alpha x) \sin (\beta y), \\
& v_{0}=\sum_{m=1}^{\infty} \sum_{n=1}^{\infty} V_{\mathrm{mn}}(t) \sin (\alpha x) \cos (\beta y), \\
& w_{0}=\sum_{m=1}^{\infty} \sum_{n=1}^{\infty} W_{\mathrm{mn}}(t) \sin (\alpha x) \sin (\beta y),
\end{aligned}
$$




$$
\begin{aligned}
& \phi_{x}=\sum_{m=1}^{\infty} \sum_{n=1}^{\infty} \phi_{\mathrm{Xmn}}(t) \cos (\alpha x) \sin (\beta y), \\
& \phi_{y}=\sum_{m=1}^{\infty} \sum_{n=1}^{\infty} \phi_{\mathrm{Ymn}}(t) \sin (\alpha x) \cos (\beta y),
\end{aligned}
$$

where $U_{\mathrm{mn}}(t), V_{\mathrm{mn}}(t), W_{0 \mathrm{mn}}(t), \varphi_{\mathrm{xmn}}(t)$, and $\varphi_{y m n}(t)$ are the parameters about time, $\alpha=m \pi / a, \beta=n \pi / b$, and $m$ and $n$ are the half-wave number of two orthogonal curvilinear coordinate directions, respectively. Assuming the periodic solution is of the form

$$
\left\{\begin{array}{c}
U_{\mathrm{mn}}(t) \\
V_{\mathrm{mn}}(t) \\
W_{\mathrm{mn}}(t) \\
\phi_{\mathrm{X} \mathrm{mn}}(t) \\
\phi_{\mathrm{Ymn}}(t)
\end{array}\right\}=\left\{\begin{array}{c}
U_{\mathrm{mn}}^{0} \\
V_{\mathrm{mn}}^{0} \\
W_{\mathrm{mn}}^{0} \\
\phi_{\mathrm{X} \mathrm{mn}}^{0} \\
\phi_{\mathrm{Y} \mathrm{mn}}^{0}
\end{array}\right\} e^{i \omega t}\left\{\begin{array}{c}
U_{\mathrm{mn}}^{0} \\
V_{\mathrm{mn}}^{0} \\
W_{\mathrm{mn}}^{0} \\
\phi_{\mathrm{X} \mathrm{mn}}^{0} \\
\phi_{\mathrm{Y} \mathrm{mn}}^{0}
\end{array}\right\} \neq 0,
$$

where $i=\sqrt{-1}$ and $\omega$ is the natural frequency of the system. By substituting equation (19) into (20), the characteristic equation of the honeycomb plate can be obtained:

$$
K-\omega^{2} M=0,
$$

where $M$ and $K$ are the mass matrix and stiffness matrix of the system, respectively. $M$ is from equation (14f) and $K$ is from equations (9) and (10); the expressions for $M$ and $K$ are similar as the Appendix of reference [23].

\section{Finite Element Analysis}

The finite element models are obtained by using ABAQUS/ Standard. An ideal elastic-plastic model is adopted, and an S4R shell element is selected for mesh generation. The Lanczos method is used to extract characteristic values for linear perturbation analysis steps and to calculate the natural frequency and corresponding array of the system. Because the theoretical model of the FGH sandwich plate above is established through the functional relationship between the physical parameters of the material and the radial position, in order to ensure the convergence of the results in the finite element method, a discrete method is adopted to solve the finite element models.

4.1. Validity of the Finite Element Model. It is necessary to test the effectiveness of the model. Taking Type A and Type B as examples, Type $A$ is made of a functionally graded surface and homogeneous ceramic material core, Type B is made of a functionally graded core and the homogeneous ceramic top face-sheet and the homogeneous metal aluminum honeycomb bottom face-sheet. Both A and B are under the four edges of a simply supported boundary. The honeycomb core layer of the sandwich plate is arranged in a concave hexagonal structure, and the lengths of the plate are $a=0.069 \mathrm{~m}$ and $b=0.067 \mathrm{~m}$, and the total thickness of the plate $h=0.045 \mathrm{~m}$. The size of the single cell $l_{1}=0.003 \mathrm{~m}, l_{2}=2 l_{1}$, and $t_{1}=t_{2}=0.001 \mathrm{~m}$. The theoretical solution by using the
Navier method and numerical results by using the FE method of sandwich plates are shown in Table 1. From the results given in Table 1, it can be seen that the theoretical solutions obtained by the Navier method are closer to the numerical results obtained by the current finite element method. Especially, it verified the correctness of the equivalent elastic parameters of the graded honeycomb core for the Type B obtained from equation (5).

4.2. Numerical Results and Discussions. The parameters of the FGH sandwich plate are chosen as follows: the length of the plate are $a=0.1 \mathrm{~m}$ and $b=0.098 \mathrm{~m}$, the total thickness of the plate $h=0.01 \mathrm{~m}$, the parameters of the honeycomb cell $l_{1}=0.005 \mathrm{~m}, l_{2}=2 l_{1}, t_{1}=t_{2}=0.001 \mathrm{~m}$, and $\theta=\pi / 6$. All the equivalent elastic parameters are calculated through formula (5). The material parameters are shown in Table 2.

Tables 3 and 4 give the natural frequencies of the functionally graded honeycomb sandwich plate for Type A and Type $\mathrm{B}$ when the volume fraction index $N$ and the core thickness change.

In order to more intuitively observe the effect of the core layer thickness and volume fraction index on functionally graded honeycomb plates, Figures 5 and 6 are obtained according to Tables 3 and 4, respectively. From Table 3 and Figure 5, it can be seen that for Type A, the natural frequencies increase when the volume fraction index $N$ increases. Compared with $N$, the core thickness has less effect on natural frequencies. As for Type B, it can be seen from Table 4 and Figure 6 that when the core is made of functionally graded materials, the effect of the volume fraction index on the natural frequencies is less than that in Type A. However, the effect of the core thickness is slightly larger than that in Type A. The case is a little bit more in type B than in type A that as the core thickness increases, the natural frequency increases and then decreases. It can be seen from Tables 3 and 4 that the natural frequencies of Type A are much higher than that of Type B with the same core thickness, same volume fraction index, and same model $(m, n)$.

\section{Performance of the FGH Sandwich Plate under Low-Speed Impact}

In this section, the energy absorptions and crushing mechanism of the FGH sandwich plate for Type A and Type $\mathrm{B}$ are analyzed and compared with the honeycomb sandwich plate without functionally graded materials named "Type C." The finite element models under impact loads are established by using ABAQUS/Explicit, as shown in Figure 7. The parameters of the plate are the same as those in Section 4. The impact object is a rigid ball with a diameter of $r=10 \mathrm{~mm}$, and its mass is $5 \mathrm{~kg}$. The boundary conditions of the lower layer are set and completely fixed, and "contact_tied_nodes_to_surface contact" is set between the upper and lower layers and the honeycomb core layer.

5.1. Analysis of Numerical Results. The ordinary nongraded honeycomb sandwich plate named "Type C" is introduced as a comparison object. Figure 8 shows the kinetic energy of the 
TABLE 1: Comparison of natural frequencies $(\mathrm{Hz})$.

\begin{tabular}{lccccc}
\hline Mode & & \multicolumn{2}{c}{ Type A } & \multicolumn{2}{c}{ Type B } \\
$m$ & $n$ & Theoretical solution & FEM result & Theoretical solution & FEM result \\
\hline 1 & 2 & 275.9721 & 276.06 & 226.9837 & 235.35 \\
2 & 1 & 288.9092 & 284.24 & 237.2282 & 239.29 \\
2 & 2 & 451.2983 & 446.08 & 355.8742 & 349.01 \\
\hline
\end{tabular}

TABLE 2: Material parameters of the FGH sandwich plate.

\begin{tabular}{lcccc}
\hline & Elasticity modulus $(\mathrm{E})(\mathrm{GPa})$ & Density $\left(\mathrm{kg} / \mathrm{m}^{3}\right)$ & Shear modulus $(\mathrm{G})(\mathrm{GPa})$ & Poisson's ratio $(\nu)$ \\
\hline Metal aluminium & 69 & 2700 & 27 & 0.3 \\
Ceramic alumina & 380 & 3800 & 146 & 0.3 \\
\hline
\end{tabular}

TABle 3: Type A: the first five natural frequencies $\omega$ of the simply supported FGH sandwich plate.

\begin{tabular}{|c|c|c|c|c|c|c|c|c|}
\hline \multirow{2}{*}{ Volume fraction index $(\mathrm{N})$} & \multirow{2}{*}{$m$} & \multirow{2}{*}{$n$} & \multicolumn{6}{|c|}{ Core thickness $\left(h_{\mathrm{c}} / \mathrm{m}\right)$} \\
\hline & & & 0.004 & 0.005 & 0.006 & 0.007 & 0.008 & 0.009 \\
\hline \multirow{5}{*}{0} & 1 & 1 & 113.1143 & 119.1696 & 125.1222 & 130.5536 & 134.4407 & 132.8545 \\
\hline & 1 & 2 & 275.9721 & 290.6332 & 304.9596 & 317.8596 & 326.8175 & 323.2968 \\
\hline & 2 & 1 & 288.9092 & 304.2515 & 319.2424 & 332.7445 & 342.1682 & 338.6695 \\
\hline & 2 & 2 & 451.2983 & 475.0157 & 497.9900 & 518.2752 & 531.6414 & 525.1794 \\
\hline & 1 & 3 & 546.5282 & 575.1648 & 602.8417 & 627.1444 & 642.9709 & 636.4158 \\
\hline \multirow{5}{*}{1} & 1 & 1 & 148.2252 & 161.6798 & 176.7878 & 193.6571 & 212.2255 & 231.0084 \\
\hline & 1 & 2 & 361.5727 & 394.2069 & 430.6859 & 470.9909 & 513.9364 & 550.1039 \\
\hline & 2 & 1 & 378.5149 & 412.6644 & 450.8250 & 492.9580 & 537.7648 & 575.2849 \\
\hline & 2 & 2 & 591.2158 & 644.2299 & 703.1958 & 767.6059 & 833.8414 & 878.1383 \\
\hline & 1 & 3 & 715.8673 & 779.8603 & 850.8524 & 927.9117 & 1005.5225 & 1049.0553 \\
\hline \multirow{5}{*}{2} & 1 & 1 & 177.6786 & 192.2506 & 207.2047 & 222.1366 & 236.3566 & 246.6403 \\
\hline & 1 & 2 & 433.3435 & 468.6475 & 504.6524 & 540.0343 & 571.8150 & 583.0676 \\
\hline & 2 & 1 & 453.6414 & 490.5800 & 528.2335 & 565.1887 & 598.2265 & 608.9659 \\
\hline & 2 & 2 & 708.4573 & 765.7574 & 823.8039 & 879.8600 & 926.9166 & 923.8460 \\
\hline & 1 & 3 & 857.7251 & 926.8319 & 996.5809 & 1063.2875 & 1117.1166 & 1100.4585 \\
\hline \multirow{5}{*}{5} & 1 & 1 & 211.5154 & 217.4290 & 224.2472 & 232.1923 & 241.0141 & 247.6679 \\
\hline & 1 & 2 & 515.5570 & 529.7031 & 545.8134 & 564.0796 & 582.5511 & 584.4944 \\
\hline & 2 & 1 & 539.6793 & 554.4651 & 571.2873 & 590.3178 & 609.4069 & 610.3341 \\
\hline & 2 & 2 & 842.3328 & 864.9783 & 890.4173 & 918.3691 & 943.4398 & 924.5607 \\
\hline & 1 & 3 & 1019.4419 & 1046.5443 & 1076.7582 & 1109.3650 & 1136.4637 & 1100.5041 \\
\hline
\end{tabular}

rigid ball with time $t$. At about $t=0.0017 \mathrm{~s}$, the rigid ball touches the upper surface of the sandwich plate. It can be seen from Figure 8 that the top blue line is the kinetic energy of the ball impacting the Type $\mathrm{C}$ honeycomb plate without being graded, which indicates that the graded honeycomb plate has a better energy absorption capacity. Table 5 shows the impact energy absorption capacity of the three honeycomb plates at the same impact velocity of the rigid ball. Type B has the strongest energy absorption capacity, followed by Type A, and Type C is the weakest. That is to say, the sandwich plate which core is made of the graded honeycomb has a strong energy absorption capacity.

In order to further compare the impact resistance of the three honeycomb sandwich plates, Figure 9 shows the contact reaction force of the rigid ball over time which means that the bearing capacity of the functionally graded honeycomb sandwich plate is higher than that of the nongraded plate. Similarly, Figure 10 shows the change of the strain energy over time which means that the graded honeycomb plates have more strain energy under the same impact load. Therefore, the combination of the two materials takes advantage of the functional graded and improves the mechanical behavior of the structure.

5.2. Influence of the Parameter on Energy Absorption of the Plate. Taking the aforementioned Type A and Type B as research objects, the effects of the volume fraction index, the thickness of the honeycomb core layer, and the impact velocity on the energy absorption capacity of the two functionally graded honeycomb sandwich plates are studied, respectively. The energy lost during the impacting is ignored in the calculation.

Table 6 represents the energy absorption capacity of the functionally graded honeycomb sandwich plates under different volume fraction indexes. It can be seen that the energy absorption capacity becomes weaker as the volume fraction index increases for Type A. While for Type B, the Sandwich plate with functionally graded honeycomb core, the energy absorption capacity becomes stronger as the 
TABLE 4: Type B: the first five natural frequencies $\omega$ of the simply supported FGH sandwich plate.

\begin{tabular}{|c|c|c|c|c|c|c|c|c|}
\hline \multirow{2}{*}{ Volume fraction index $(\mathrm{N})$} & \multirow{2}{*}{$m$} & \multirow{2}{*}{$n$} & \multicolumn{6}{|c|}{ Core thickness $\left(h_{\mathrm{c}} / \mathrm{m}\right)$} \\
\hline & & & 0.004 & 0.005 & 0.006 & 0.007 & 0.008 & 0.009 \\
\hline \multirow{5}{*}{0} & 1 & 1 & 93.8293 & 98.76310237 & 103.5649 & 107.8586 & 110.7274 & 108.5318 \\
\hline & 1 & 2 & 226.9837 & 238.1190884 & 248.6973 & 257.9076 & 264.0070 & 260.1520 \\
\hline & 2 & 1 & 237.2285 & 248.7270141 & 259.6171 & 269.0838 & 275.3979 & 271.6402 \\
\hline & 2 & 2 & 355.8742 & 369.0205917 & 380.7708 & 390.4503 & 396.5941 & 392.4074 \\
\hline & 1 & 3 & 414.6251 & 427.054062 & 438.0477 & 447.2150 & 453.5988 & 452.2424 \\
\hline \multirow{5}{*}{1} & 1 & 1 & 93.9876 & 99.0091734 & 103.9421 & 108.4404 & 111.6602 & 110.3572 \\
\hline & 1 & 2 & 227.3491 & 238.6789793 & 249.5414 & 259.1763 & 265.9495 & 264.0463 \\
\hline & 2 & 1 & 237.6063 & 249.3051434 & 260.4864 & 270.3873 & 277.4007 & 275.7181 \\
\hline & 2 & 2 & 356.4367 & 369.9074751 & 382.1595 & 392.6546 & 400.2923 & 400.5990 \\
\hline & 1 & 3 & 415.2020 & 427.9615474 & 439.4731 & 449.5008 & 457.5133 & 461.1549 \\
\hline \multirow{5}{*}{2} & 1 & 1 & 94.0404 & 99.0913374 & 104.0678 & 108.6324 & 111.9534 & 110.9047 \\
\hline & 1 & 2 & 227.4669 & 238.8557671 & 249.7981 & 259.5354 & 266.3934 & 264.7569 \\
\hline & 2 & 1 & 237.7276 & 249.4855364 & 260.7459 & 270.7446 & 277.8313 & 276.4339 \\
\hline & 2 & 2 & 356.5854 & 370.1171245 & 382.4453 & 393.0287 & 400.7142 & 401.2751 \\
\hline & 1 & 3 & 415.3283 & 428.1261526 & 439.6789 & 449.7417 & 457.7164 & 461.3341 \\
\hline \multirow{5}{*}{5} & 1 & 1 & 94.0933 & 99.17355126 & 104.1936 & 108.8238 & 112.2351 & 111.3560 \\
\hline & 1 & 2 & 227.5803 & 239.0210756 & 250.0285 & 259.8343 & 266.6629 & 264.7135 \\
\hline & 2 & 1 & 237.8432 & 249.6518918 & 260.9730 & 271.0286 & 278.0539 & 276.3188 \\
\hline & 2 & 2 & 356.7005 & 370.2522101 & 382.5782 & 393.0962 & 400.4581 & 399.8910 \\
\hline & 1 & 3 & 415.3939 & 428.1643223 & 439.6385 & 449.5104 & 456.9349 & 458.6987 \\
\hline
\end{tabular}

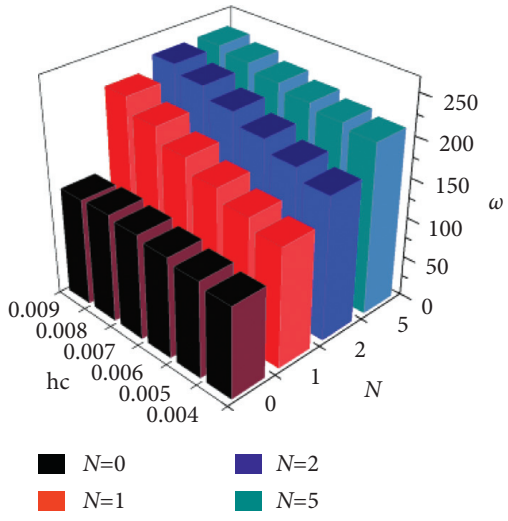

(a)

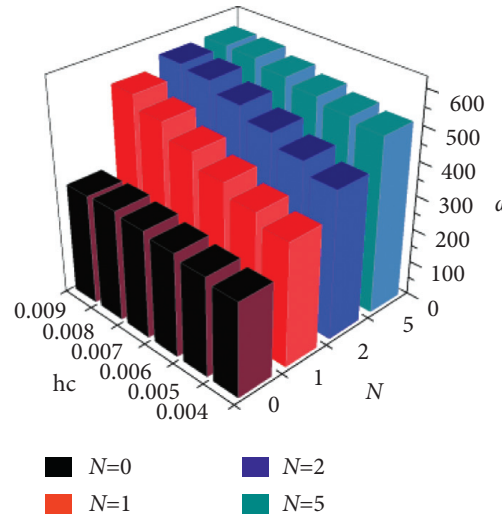

(b)

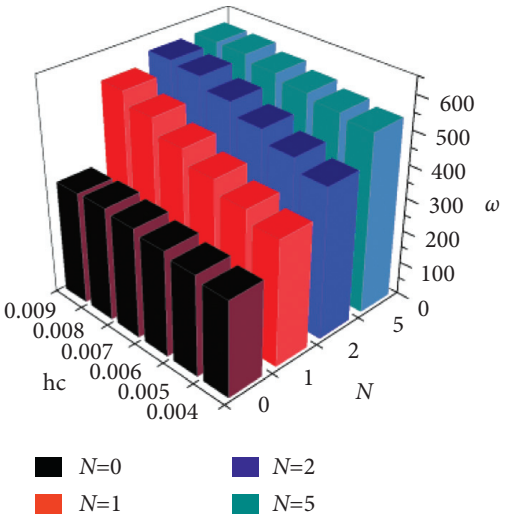

(c)

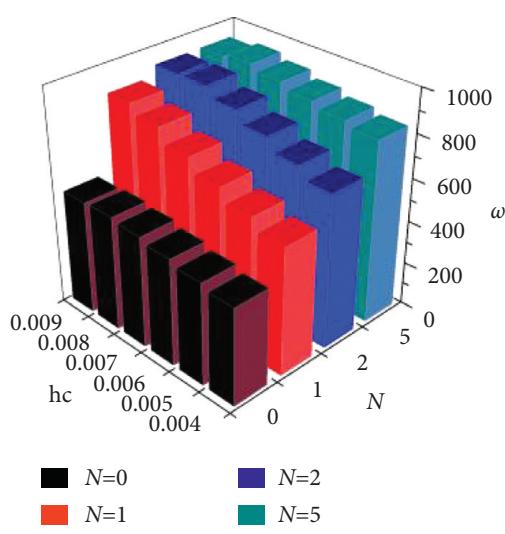

(d)

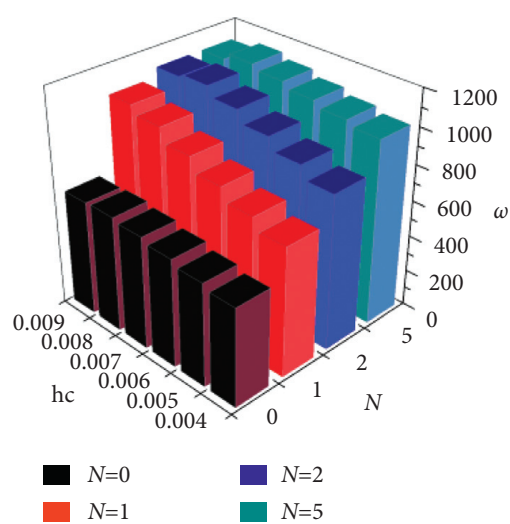

(e)

Figure 5: Type A first five natural frequencies $\omega$ of the simply supported FGM sandwich plate: (a) $1^{\text {st }}$ natural frequency, (b) $2^{\text {nd }}$ natural frequency, (c) $3^{\text {rd }}$ natural frequency, (d) $4^{\text {th }}$ natural frequency, and (e) $5^{\text {th }}$ natural frequency. 


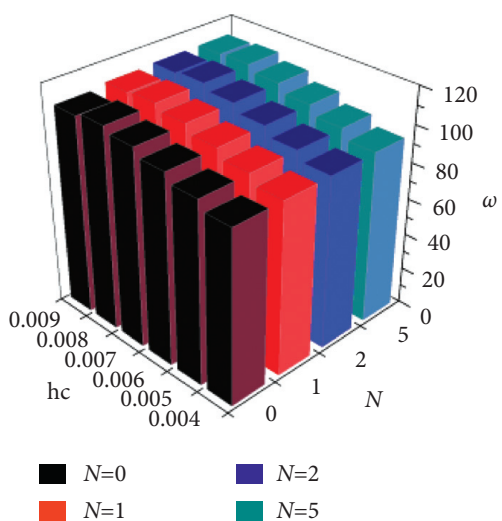

(a)

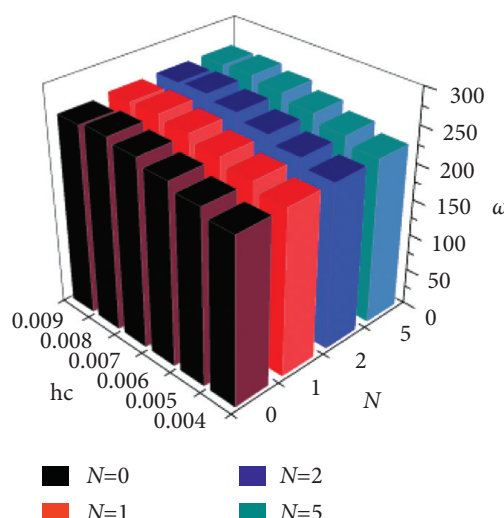

(b)

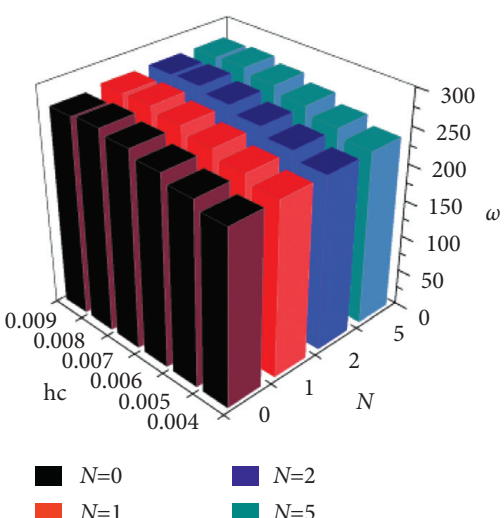

(c)

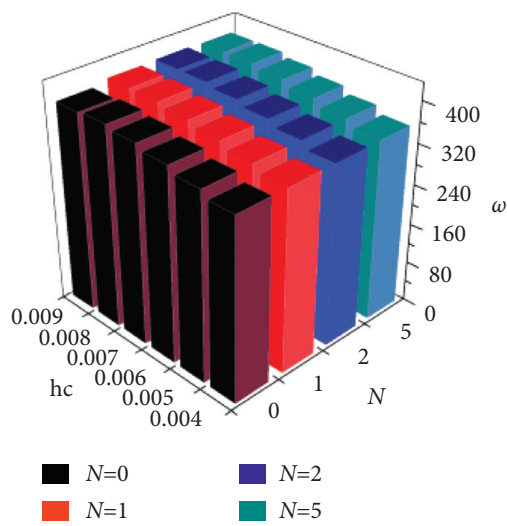

(d)

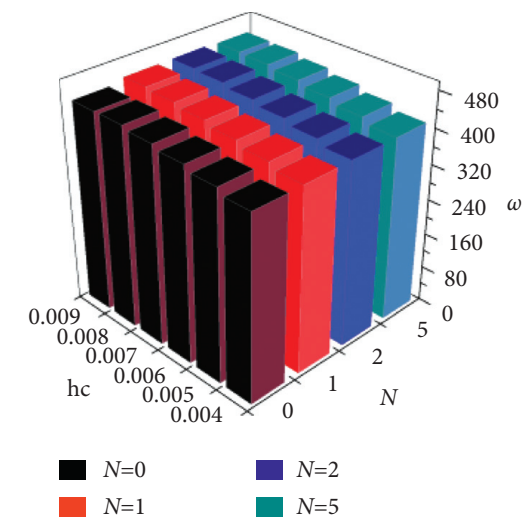

(e)

Figure 6: Type B first five natural frequencies $\omega$ of simply supported FGM sandwich plate: (a) $1^{\text {st }}$ natural frequency, (b) $2^{\text {nd }}$ natural frequency, and (c) $3^{\text {rd }}$ natural frequency.

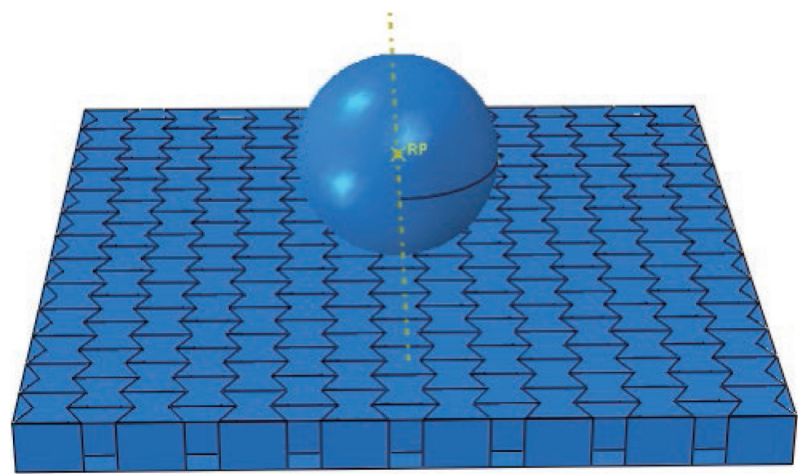

Figure 7: FE model of the FGH sandwich plate under impact.

volume fraction index increases. Furthermore, under the same volume fraction index, the energy absorption capacity of type $\mathrm{B}$ is stronger than type A.

Table 7 shows the energy absorption capacity of the two plates with different core thickness. For Type A, as the thickness of the honeycomb core layer increases, the energy absorption capacity decreases. Because the honeycomb core layer of Type $\mathrm{A}$ is a homogeneous ceramic material, with the increase in thickness and increase in ceramic materials, so the energy absorption capacity is weakened. For Type B, as the thickness of the honeycomb

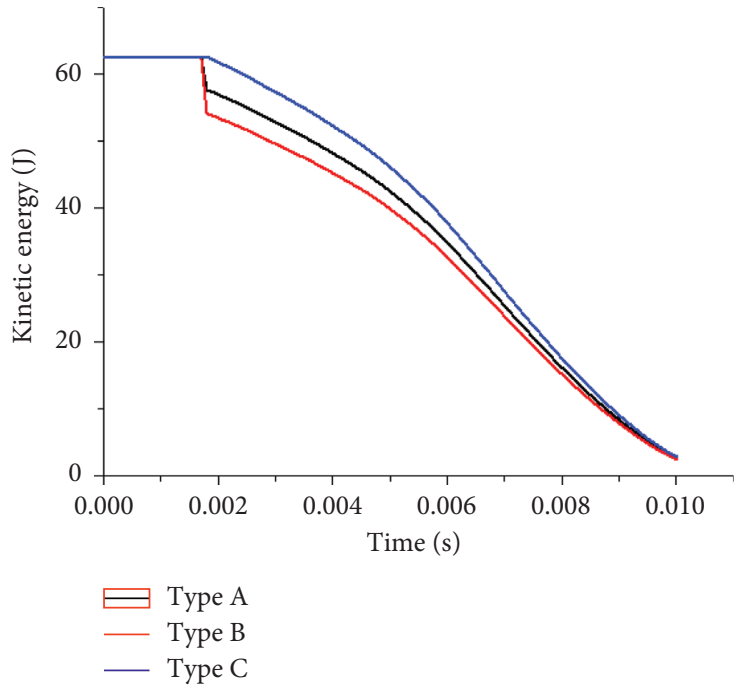

FIGURE 8: Impact kinetic energy-time history of the rigid ball.

core layer increases, the energy absorption capacity becomes stronger. This is because the honeycomb core layer of Type B is the functionally graded layer composed of ceramics and metals. The structural advantages of functional graded materials are fully utilized for Type B under impact loads. 
TABLE 5: Energy absorption characteristics of the three types of the honeycomb sandwich plates.

\begin{tabular}{lcccc}
\hline Structure type & Initial impact velocity $(\mathrm{m} / \mathrm{s})$ & Initial kinetic energy $(\mathrm{J})$ & Absorbing energy $(\mathrm{J})$ & Energy absorption rate \\
\hline Type A & 5 & 62.5 & 59.93 & $95.88 \%$ \\
Type B & 5 & 62.5 & 60.09 & $96.14 \%$ \\
Type C & 5 & 62.5 & 58.91 & $95.53 \%$ \\
\hline
\end{tabular}

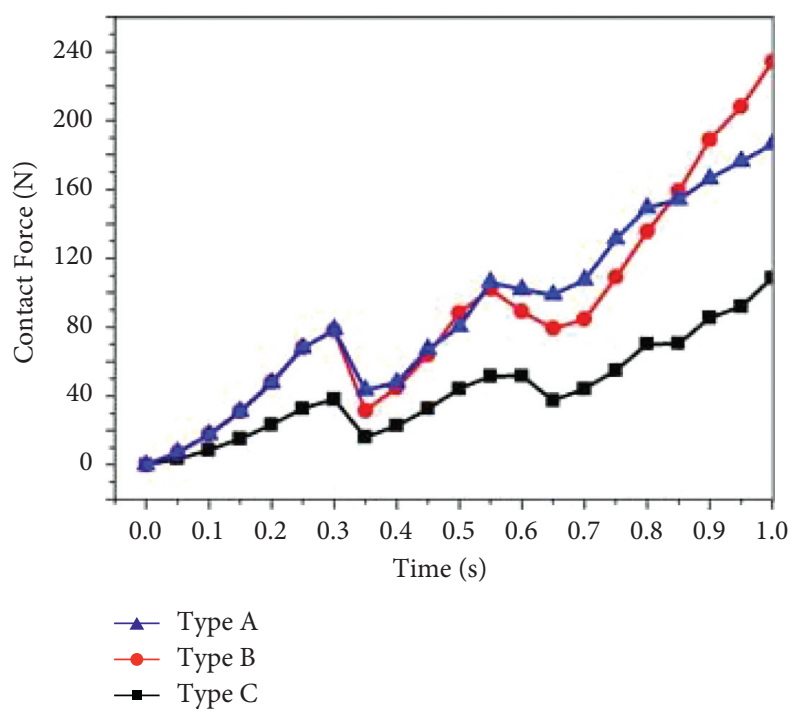

FIgURE 9: Contact force-time history curve of steel ball.

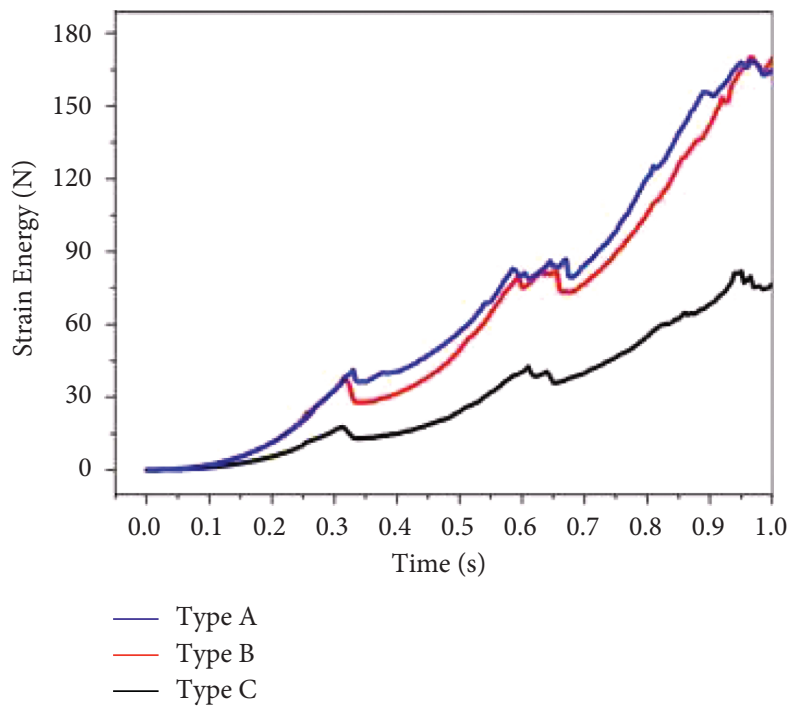

Figure 10: Strain energy-time history curve of plate.

Figure 11 gives the energy absorption-time curve with different initial impact velocities. It can be obtained that the energy absorption capacity begins to decrease at about $0.08 \mathrm{~s}$; then, brittle failure occurs in the honeycomb core. With the increase of the impact speed, the energy absorption capacity curve of the FGM honeycomb plate appears at a peak point and then decreases sharply; that is, the greater the impact speed is, the stronger the impact damage of the honeycomb core is. It can be concluded that the energy absorption capacity of the honeycomb sandwich plate under low-speed impact is better. By comparing Figures 11(a) and 11(b), it can be seen that the impact resistance of Type $B$ is a bit longer than Type A.

The central deflections of the sandwich plates under the impact load are derived. The parameters chosen are the same as above except for the ones that need to be changed. Table 8 provides the central deflections among the three plates; it can be obtained that the deflections of Type B with graded honeycomb core are relatively small. Since Type A and Type $\mathrm{B}$ contain ceramics, its Young's modulus is greater than 
TABLE 6: Energy absorption capacity with different volume fraction indexes.

\begin{tabular}{|c|c|c|c|c|c|c|}
\hline \multirow{2}{*}{$\begin{array}{l}\text { Volume fraction } \\
\text { index }(\mathrm{N})\end{array}$} & \multicolumn{3}{|c|}{ Type A } & \multicolumn{3}{|c|}{ Type B } \\
\hline & $\begin{array}{c}\text { Initial kinetic } \\
\text { energy }(\mathrm{J})\end{array}$ & $\begin{array}{l}\text { Absorbing } \\
\text { energy }(\mathrm{J})\end{array}$ & $\begin{array}{c}\text { Energy absorption } \\
\text { rate }(\%)\end{array}$ & $\begin{array}{c}\text { Initial kinetic } \\
\text { energy }(\mathrm{J})\end{array}$ & $\begin{array}{l}\text { Absorbing } \\
\text { energy }(\mathrm{J})\end{array}$ & $\begin{array}{c}\text { Energy absorption } \\
\text { rate }(\%)\end{array}$ \\
\hline 0 & 62.5 & 59.93 & 95.88 & 62.5 & 60.09 & 95.88 \\
\hline 1 & 62.5 & 59.74 & 95.58 & 62.5 & 60.30 & 96.48 \\
\hline 2 & 62.5 & 59.60 & 95.36 & 62.5 & 60.56 & 96.89 \\
\hline 5 & 62.5 & 59.45 & 95.12 & 62.5 & 60.62 & 96.99 \\
\hline
\end{tabular}

TABLE 7: Energy absorption capacity with different thicknesses of honeycomb cores.

\begin{tabular}{|c|c|c|c|c|c|c|}
\hline \multirow[b]{2}{*}{$\begin{array}{l}\text { Honeycomb core } \\
\text { thickness }(\mathrm{mm})\end{array}$} & \multicolumn{3}{|c|}{ Type A } & \multicolumn{3}{|c|}{ Type B } \\
\hline & $\begin{array}{c}\text { Initial kinetic } \\
\text { energy }(\mathrm{J})\end{array}$ & $\begin{array}{l}\text { Absorbing } \\
\text { energy }(\mathrm{J})\end{array}$ & $\begin{array}{c}\text { Energy absorption } \\
\text { rate }(\%)\end{array}$ & $\begin{array}{c}\text { Initial kinetic } \\
\text { energy }(\mathrm{J})\end{array}$ & $\begin{array}{l}\text { Absorbing } \\
\text { energy }(\mathrm{J})\end{array}$ & $\begin{array}{c}\text { Energy absorption } \\
\text { rate }(\%)\end{array}$ \\
\hline 4 & 62.5 & 59.93 & 95.88 & 62.5 & 60.09 & 95.88 \\
\hline 5 & 62.5 & 58.72 & 93.95 & 62.5 & 60.24 & 96.38 \\
\hline 6 & 62.5 & 57.26 & 91.61 & 62.5 & 60.38 & 96.60 \\
\hline 7 & 62.5 & 55.58 & 88.92 & 62.5 & 60.45 & 96.72 \\
\hline 8 & 62.5 & 54.22 & 86.75 & 62.5 & 60.45 & 96.72 \\
\hline 9 & 62.5 & 54.05 & 86.48 & 62.5 & 60.46 & 96.73 \\
\hline
\end{tabular}

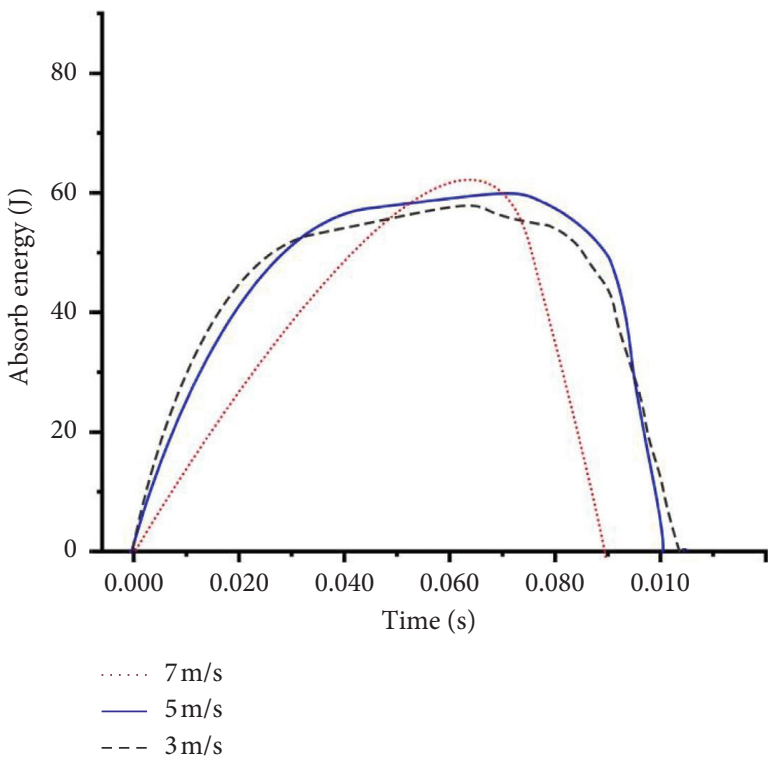

(a)

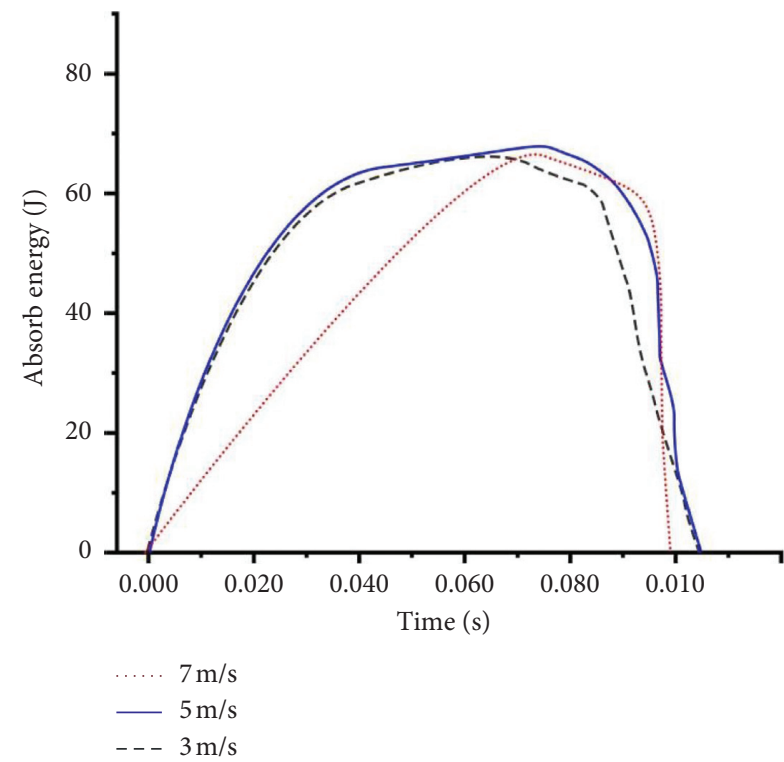

(b)

FIgURE 11: Energy absorption capacity with different initial impact velocities. (a) Type A. (b) Type B.

TABLE 8: Central deflections of three plates under same impact velocity.

\begin{tabular}{lcr}
\hline Structure type & Initial impact velocity $(\mathrm{m} / \mathrm{s})$ & Central deflections $(\mathrm{mm})$ \\
\hline Type A & 5 & 5.156 \\
Type B & 5 & 5.155 \\
Type C & 5 & 5.192 \\
\hline
\end{tabular}

TABle 9: Central deflections of the plates with different volume fraction indexes.

\begin{tabular}{lcc}
\hline Volume fraction index $(\mathrm{N})$ & $\begin{array}{c}\text { Central deflections }(\mathrm{mm}) \\
\text { Type A }\end{array}$ & $\begin{array}{c}\text { Central deflections (mm) } \\
\text { Type B }\end{array}$ \\
\hline 0 & 5.187 & 5.151 \\
1 & 5.171 & 5.15 \\
2 & 5.156 & 5.155 \\
5 & 5.156 & 5.152 \\
\hline
\end{tabular}


aluminum. by calculations, the central deflections increase when the impact speed increases; the deflections of Type B are $3.098,5.155$, and 7.177 when the impact velocities are 3, 5 , and 7 , respectively.

The central deflections are given when the volume fraction index $N$ is changed. It can be seen from Table 9 that the volume fraction index has less influence on Type B. The rigid ball impacts from the top, while the upper face of Type $A$ is metal and Type B is ceramic; therefore, the deflection of Type A is a little larger than Type B.

\section{Conclusions}

In this paper, the equivalent elastic parameters of the functionally graded honeycomb core are given; on this basis, the model of the sandwich plate is obtained by using the HSDT. The Navier method is used to compute the natural frequencies of the plate. The natural frequencies from the finite element model are compared which prove the effectiveness of equivalent parameters and the model of the graded honeycomb sandwich plate. The following conclusions can be drawn from the analysis of the results from this paper.

(1) This paper derived the equivalent elastic parameters of the honeycomb core layer are applicable to the functionally graded honeycomb sandwich plate.

(2) When the volume fraction index increases, the natural frequencies increase and Type $\mathrm{A}$ increases more than Type B.

(3) When the thickness of the core layer increases, the natural frequencies increase but drop slightly when the core layer thickness is larger than $0.008 \mathrm{~m}$. This is because as the thickness of the core layer increases, the facesheet becomes very thin. The change of the natural frequencies for Type $\mathrm{A}$ is larger than that of Type B.

(4) The energy absorption capacity of Type A decreases with the volume fraction index or the thickness of the core layer increases, while Type B's increases. The functionally graded honeycomb sandwich plate exhibits good energy absorption and impact resistance under low-speed impact.

\section{Data Availability}

The data included in this study are available from the corresponding author upon request.

\section{Conflicts of Interest}

The authors declare that they have no conflicts of interest.

\section{Acknowledgments}

The authors gratefully acknowledge the support of the National Natural Science Foundation of China (Nos. 11732005 and 11902038). Hebei Provincial Natural Science Foundation of China (No. A2019202342), the Project of
Promoting the Connotation Development of Colleges and Universities (No. 2020KYNH204), Qin Xin Talents Cultivation Program of the Beijing Information Science and Technology University (No. QXTCP C202101).

\section{References}

[1] S. Nikbakht, S. Kamarian, and M. Shakeri, "A review on optimization of composite structures Part II: functionally graded materials," Composite Structures, vol. 214, pp. 83-102, 2019.

[2] W. Zhang, Y. X. Hao, and J. Yang, "Nonlinear dynamics of FGM circular cylindrical shell with clamped-clamped edges," Composite Structures, vol. 94, no. 3, pp. 1075-1086, 2012.

[3] M. Yao, Y. Niu, and Y. Hao, "Nonlinear dynamic responses of rotating pretwisted cylindrical shells," Nonlinear Dynamics, vol. 95, no. 1, pp. 151-174, 2019.

[4] Y. X. Hao, M. X. Wang, W. Zhang, S. W. Yang, L. T. Liu, and Y. H. Qian, "Bending-torsion coupling bursting oscillation of a sandwich conical panel under parametric excitation," Journal of Sound and Vibration, vol. 495, Article ID 115904, 2021.

[5] Y. Liu, Z. Qin, and F. Chu, "Nonlinear forced vibrations of FGM sandwich cylindrical shells with porosities on an elastic substrate," Nonlinear Dynamics, vol. 104, no. 2, pp. 1007-1021, 2021.

[6] L. J. Gibson and M. F. Ashby, "Cellular solid," Structure and Properties, Cambridge University Press, vol. 33, no. 11, pp. 30-40, Cambridge, England, 1997.

[7] E. Hamidreza and M. N. Farid, "Vibrational behavior of composite cylindrical shells with auxetic honeycombs core layer subjected to a moving pressure," Composite Structures, vol. 254, Article ID 112847, 2020.

[8] X. C. Zhang, C. C. An, Z. F. Shen, H. X. Wu, W. G. Yang, and J. P. Bai, "Dynamic crushing responses of bio-inspired reentrant auxetic honeycombs under in-plane impact loading," Materials Today Communications, vol. 23, Article ID 100918, 2020.

[9] N. D. Duc, K. E. Seung, N. D. Tuan, P. Tran, and N. D. Khoa, "New approach to study nonlinear dynamic response and vibration of sandwich composite cylindrical panels with auxetic honeycomb core layer," Aerospace Science and Technology, vol. 70, pp. 396-404, 2017.

[10] W. Hui, H. Ohtaki, S. Kotosaka, and G. Hu, "A study of negative Poisson's ratio in auxetic honeycombs based on a large deflection mode," European Journal of Mechanics - A: Solids, vol. 23, no. 1, pp. 95-106, 2004.

[11] M. Xu, D. Liu, P. Wang et al., "In-plane compression behavior of hybrid honeycomb metastructures: theoretical and experimental studies," Aerospace Science and Technology, vol. 106, Article ID 106081, 2020.

[12] W. Zhang, J. E. Chen, D. X. Cao, and L. H. Chen, "Nonlinear dynamic responses of a truss core sandwich plate," Composite Structures, vol. 108, pp. 367-386, 2014.

[13] B. Safaei and A. M. Fattahi, "Free vibrational response of single-layered graphene sheets embedded in an elastic matrix using different nonlocal plate models," Mechanika, vol. 23, no. 5, pp. 678-687, 2017.

[14] B. Safaei, "Frequency-dependent damped vibrations of multifunctional foam plates sandwiched and integrated by composite faces," The European Physical Journal Plus, vol. 136, no. 6, 2021.

[15] G. Palomba, G. Epasto, V. Crupi, and E. Guglielmino, "Single and double-layer honeycomb sandwich panels under impact 
loading," International Journal of Impact Engineering, vol. 121, pp. 77-90, 2018.

[16] B. Yu, B. Han, P. B. Su, C. Y. Ni, Q. C. Zhang, and T. J. Lu, "Graded square honeycomb as sandwich core for enhanced mechanical performance," Materials \& Design, vol. 89, pp. 642-652, 2016.

[17] W. H. Xie, S. H. Meng, L. Ding et al., "High-temperature highvelocity impact on honeycomb sandwich panels," Composites Part B: Engineering, vol. 138, pp. 1-11, 2018.

[18] X. Ma, X. Li, S. Li, R. Li, Z. Wang, and G. Wu, "Blast response of gradient honeycomb sandwich panels with basalt fiber metal laminates as skins," International Journal of Impact Engineering, vol. 123, pp. 126-139, 2019.

[19] K. Arslan and R. Gunes, "Experimental damage evaluation of honeycomb sandwich structures with Al/B4C FGM face plates under high velocity impact loads," Composite Structures, vol. 202, pp. 304-312, 2018.

[20] S. Li, X. Li, Z. Wang, G. Wu, G. Lu, and L. Zhao, "Sandwich panels with layered graded aluminum honeycomb cores under blast loading," Composite Structures, vol. 173, pp. 242-254, 2017.

[21] Y. Hao, Z. Li, W. Zhang, S. Li, and M. Yao, "Vibration of functionally graded sandwich doubly curved shells using improved shear deformation theory," Science China Technological Sciences, vol. 61, no. 6, pp. 791-808, 2018.

[22] X. Zhu, J. Zhang, W. Zhang, and J. Chen, "Vibration frequencies and energies of an auxetic honeycomb sandwich plate," Mechanics of Advanced Materials and Structures, vol. 26, no. 23, pp. 1951-1957, 2019.

[23] Q. Li, V. P. Iu, and K. P. Kou, "Three-dimensional vibration analysis of functionally graded material sandwich plates," Journal of Sound and Vibration, vol. 311, no. 1-2, pp. 498-515, 2008. 